\title{
The Synthetic Compound Norcantharidin Induced Apoptosis in Mantle Cell Lymphoma In Vivo and In Vitro through the PI3K-Akt-NF- $\kappa$ B Signaling Pathway
}

\author{
Hongyan Lv, Yan Li, Hengfei Du, Jie Fang, Xiaoning Song, and Jinqiao Zhang \\ Department of Hematology, Third Hospital of Hebei Medical University, 139 Ziqiang Road, Shijiazhuang 050051, China \\ Correspondence should be addressed to Jinqiao Zhang; zhjq72@163.com
}

Received 24 February 2013; Revised 30 May 2013; Accepted 10 June 2013

Academic Editor: Shrikant Anant

Copyright (c) 2013 Hongyan Lv et al. This is an open access article distributed under the Creative Commons Attribution License, which permits unrestricted use, distribution, and reproduction in any medium, provided the original work is properly cited.

\begin{abstract}
This study aimed to elucidate the antitumor activity of norcantharidin (NCTD) against human mantle cell lymphoma (MCL). Cell proliferation and apoptosis were examined by MTS and flow cytometry. Caspase-3, -8 , and -9 activities were detected with a colorimetric caspase protease assay. Apoptotic proteins_including PARP, cyclin D1, Bcl-2 family proteins, XIAP, and cIAP I-were studied by western blot. The phosphoinositide 3 kinase (PI3K) inhibitor LY294002 was used to investigate the involvement of the PI3K/Akt signaling pathway. In vivo studies were performed using Z138 cell xenografts in nude mice. NCTD inhibited proliferation and induced apoptosis of Z138 and Mino cells, both in vitro and in vivo. PI3Kp110 $\alpha$ and p-Akt expressions were downregulated by NCTD treatment. NCTD downregulated NF- $\kappa$ B activity by preventing NF- $\kappa$ B phosphorylation and nuclear translocation. This effect was correlated with the suppression of NF- $\kappa \mathrm{B}$-regulated gene products, such as cyclin D1, BAX, survivin, Bcl-2, XIAP, and cIAP. This phenomenon was blocked by the PI3K inhibitor LY294002. Our results demonstrated that NCTD can induce growth arrest and apoptosis in MCL cells and that the mechanism may involve the PI3K/Akt/NF- $\kappa$ B signaling pathway. NCTD may have therapeutic and/or adjuvant therapeutic applications in the treatment of MCL.
\end{abstract}

\section{Introduction}

Mantle cell lymphoma (MCL) is a heterogeneous aggressive lymphoid malignancy that accounts for approximately $3-8 \%$ of non-Hodgkin's lymphoma (NHL) cases; it is characterized by the nonrandom chromosomal translocation $\mathrm{t}(11,14)$ (q13; 32) and leads to overexpression of cyclin D1 [1]. There is currently no defined standard of care for patients with MCL. High-dose, multiagent chemotherapy induces high remission rates in previously untreated patients with MCL; however, relapse commonly occurs with a rather short median survival of 5 to 7 years $[2,3]$. Clearly, novel agents and strategies are needed to improve clinical outcomes for patients with MCL [4].

Cantharidin, the Chinese blister beetle, has anticarcinogenic properties. However, its severe urinary side effects limit its clinical application. Norcantharidin (NCTD), the demethylated form of cantharidin, has higher anticancer potentials, less nephrotoxicity, and fewer inflammatory side effects than cantharidin. NCTD also has the ability to increase white cells. Recent in vitro and in vivo studies have demonstrated that NCTD can inhibit tumor cell growth, including breast cancer, hepatoma, lung cancer, colorectal adenocarcinoma, and leukemic cells, while not harming normal hematopoietic cells [5-13].

The antitumor mechanisms of NCTD are complex and poorly understood. Our previous study demonstrated that NCTD inhibits multiple myeloma cell growth and potentiates the antimyeloma effect of bortezomib by downregulating expression of the NF- $\kappa \mathrm{B}$ signal pathway [13]. In the present study, we evaluated both in vitro and in vivo anticancer activities of NCTD in MCL models with the aim of providing experimental therapeutic data to expand its indications in clinical trials.

\section{Materials and Methods}

2.1. Cell Culture and Reagents. The human mantle cell lines Z138 and Mino were cultured in PRMI-1640 medium 
(Gibco BRL, Gaithersburg, MD, USA) containing 10\% heatinactivated fetal bovine serum (FBS; Gibco) in a humidified incubator with $5 \% \mathrm{CO}_{2}$ at $37^{\circ} \mathrm{C}$. NCTD (molecular weight $368.4,>99 \%$ ) was purchased from Sigma Chemical Co. (St. Louis, MO, USA). Primary tumor cells were isolated from the peripheral blood of six MCL patients; all samples contained at least $85 \% \mathrm{CD} 19^{+} / \mathrm{CD} 20^{+} \mathrm{B}$ cells as detected by flow cytometry. Informed consent was obtained according to the Declaration of Helsinki, and the protocol was approved by the Third Hospital of Hebei Medical University Investigational Review Board.

The annexin $\mathrm{V}$ staining kit was obtained from BD PharMingen (San Diego, CA, USA). Monoclonal antibodies against PARP, c-myc, cIAP1, XIAP, nuclear factor- $\kappa \mathrm{B}$ p65 (NF- $\kappa \mathrm{B}$ p65), the inhibitor of NF- $\kappa \mathrm{B}$ alpha $(\mathrm{I} \kappa \mathrm{B} \alpha)$, $\mathrm{I} \kappa \mathrm{B}$ kinase $(\mathrm{IKK} \alpha)$, and phosphorylated $\mathrm{I} \kappa \mathrm{B} \alpha(\mathrm{p}-\mathrm{I} \kappa \mathrm{B} \alpha)$, PI3Kp110 $\alpha$, Akt, and phospho-Akt (p-Akt) were obtained from Cell Signaling Technology (Danvers, MA, USA). Antibodies against $\mathrm{Bcl}-2$, survivin, $\beta$-actin, and lamin $\mathrm{B}$ were from Santa Cruz Biotechnology (Santa Cruz, CA, USA). The Caspase Colorimetric Assay Kit was purchased from KeyGen Biotech Co., Ltd. (Nanjing, China). The phosphoinositide 3 kinase (PI3K) inhibitor LY294002 and the pan-caspase inhibitor carbobenzoxy-valyl-alanyl-aspartyl[O-methyl]-fluoromethylketone (Z-VAD) were purchased from Cell Signaling (Boston, MA, USA) and BioVision Technology, Inc. (Mountain View, CA, USA), respectively.

2.2. Cell Viability and Apoptosis Assays. The inhibitory effects of NCTD on MCL cell growth were determined by MTS with a CellTiter 96 AQueous Non-Radioactive Proliferation Assay (Promega). Z138 and Mino cells were treated with NCTD $(0$, $2.5,5,10,20$, or $40 \mu \mathrm{M})$ for 24,48 , and $72 \mathrm{~h}$. At the end of culturing, $20 \mu \mathrm{L}$ reagent was added to the culture medium and incubated for $3 \mathrm{~h}$. The absorbance of formazan was measured at $490 \mathrm{~nm}$. All experiments were performed in triplicate and repeated three times. The cell sensitivity to NCTD was expressed as the IC50 (50\% inhibitory concentration).

Apoptosis was quantitatively determined by performing annexin V/PI staining following the manufacturer's directions. Cells were incubated with different concentration of $\operatorname{NCTD}(0,2.5,5,10,20$, or $40 \mu \mathrm{M})$ for $24 \mathrm{~h}$. Approximately, $1 \times 10^{6}$ cells were resuspended in $100 \mu \mathrm{L}$ binding buffer containing FITC-conjugated annexin V. PI was added, and cell analysis and data acquisition were performed using a flow cytometer (Beckman Coulter, Brea, CA, USA).

2.3. Spectrophotometric Detection of Caspase-3, -8, and -9 Activities. Cells were treated with different concentrations of $\operatorname{NCTD}(0,2.5,5,10,20$, or $40 \mu \mathrm{M})$ for $24 \mathrm{~h}$ or with $5 \mu \mathrm{M}$ NCTD for 12, 24, 36, and $48 \mathrm{~h}$. Caspase-3, -8 , and -9 activities were determined using the Caspase Colorimetric Assay Kit according to the manufacturer's instruction. Briefly, cell lysate (100 $\mu$ g total protein) was added to a reaction mixture, which contained colorimetric substrate peptides specific to caspase$3,-8$, or -9 . The reaction was incubated at $37^{\circ} \mathrm{C}$ for $4 \mathrm{~h}$. A spectrophotometer was used to measure the absorbance at $405 \mathrm{~nm}$, and the caspase activities were expressed as the ratio OD inducer/OD control.
2.4. Cell Cycle Analysis. Cell cycle distribution was determined by staining DNA with PI (Sigma). Briefly, U266 cells were incubated with $0,5,10$, and $20 \mu \mathrm{M}$ NCTD for $24 \mathrm{~h}$. Approximately $1 \times 10^{6}$ cells were collected and fixed in $70 \%$ ice-cold ethanol. Cell pellets were suspended in PI with simultaneous RNase treatment at $37^{\circ} \mathrm{C}$ for $30 \mathrm{~min}$. Data acquisition and analysis were performed on a flow cytometer (Beckman Coulter).

2.5. Nuclear and Cytoplasmic Protein Fractionation. Z138 and Mino cells were treated with $\operatorname{NCTD}(0,5$, and $10 \mu \mathrm{M})$ for $24 \mathrm{~h}$. Nuclear and cytoplasmic proteins were extracted as previously described [13]. Cells were incubated in lysis buffer A (10 mM HEPES; 10 mM KCl; 0.1 mM EDTA, pH 6.8; $0.1 \mathrm{mM}$ EGTA, pH 7.0; and 1.0 mM DTT) containing protease and phosphate inhibitors. Then, $10 \%$ NP-40 was added, the mixture was vortexed and microcentrifuged, and the supernatants were collected as cytoplasmic protein extracts. The pellets were resuspended in $25 \mathrm{~mL}$ buffer B (20 mM HEPES, pH 7.9; 400 mM NaCl; 1.0 mM EDTA, pH 8.0; 1.0 mM EGTA, $\mathrm{pH} 7.0$; and $1.0 \mathrm{mM}$ DTT) with $\times 1$ protease and phosphate inhibitors, incubated for $30 \mathrm{~min}$, and then centrifuged. The supernatants were collected as nuclear protein extracts.

2.6. Total Protein Extraction and Western Blot. Z138 and Mino cells were treated with $\operatorname{NCTD}(0,5$, and $10 \mu \mathrm{M})$ for $24 \mathrm{~h}$. Equal amounts of lysate $(40 \mathrm{mg})$ were separated by sodium dodecyl sulfate polyacrylamide gel electrophoresis (SDS-PAGE) and then transferred onto a polyvinylidene fluoride (PVDF) membrane. The membrane was incubated with blocking buffer and then immunoblotted with primary antibodies overnight at $4^{\circ} \mathrm{C}$. Then the membrane was incubated with IRDye infrared secondary antibodies for $1 \mathrm{~h}$ at room temperature. The membrane was visualized with the Odyssey Infrared Imaging System (Lincoln, NE, USA).

2.7. Quantitative Real-Time PCR (Q-PCR) and Semiquantitative RT-PCR. Z138 cells were treated with different concentrations of $\operatorname{NCTD}(0,5$, and $10 \mu \mathrm{M})$ for $24 \mathrm{~h}$ and then harvested. Total RNA was extracted using TRIzol reagent according to the kit protocol (Invitrogen, Beijing, China). cDNA was reverse-transcribed using the PrimeScript RT Reagent Kit (TaKaRa, Dalian, China) according to the manufacturer's instructions. The Q-PCR reaction was performed following the kit protocol (TaKaRa Bio, Dalian, China), and amplification was performed using the ABI PRISM 7500 Real-Time PCR System (Applied Biosystems, CA, USA). The relative mRNA expression of each gene was normalized to GAPDH RNA levels and analyzed using the $2^{-\Delta \Delta C T}$ method. The primers were synthesized by Sangon Bioteck (Shanghai, China). The primer sequences are shown in Table 1.

For semiquantitative RT-PCR, PIK3CA and the housekeeping gene GAPDH were amplified using the primers listed in Table 1. PCR products were separated on 1.5\% agarose gels and visualized. Images were captured with Image-Pro Plus Analysis Software (Media Cybernetics, Inc., USA) and used for densitometric analysis. 
TABLE 1: List of primer sequences for RT-PCR.

\begin{tabular}{|c|c|c|c|}
\hline Gene & Forward primer sequence & Reverse primer sequence & Size (bp) \\
\hline Cyclin D1 & $5^{\prime}$-CTCCTGGTGAACAAGCTCAA-3' & 5'-TGAACTTCACATCTGTGGCA-3' & 160 \\
\hline XIAP & $5^{\prime}$-AGCTTGCAAGAGCTGGATTT-3' & $5^{\prime}$-ATTTGCACCCTGGATACCAT-3' & 138 \\
\hline cIAP1 & $5^{\prime}$-AGAATTGGCAAGAGCTGGTT-3' & $5^{\prime}$-CCGGTGTTCTGACATAGCAT-3' & 118 \\
\hline Survivin & 5'-CCTGGCAGCCCTTTCTCA-3' & $5^{\prime}$-TCAGTGGGGCAGTGGATG-3' & 121 \\
\hline Bcl-2 & $5^{\prime}$-AGTACCTGAACCGGCACCT-3' & $5^{\prime}$-CAGCCAGGAGAAATCAAACA-3' & 110 \\
\hline Bax & 5'-TTGCTTCAGGGTTTCATCC-3' & 5'-GACACTCGCTCAGCTTCTTG-3' & 112 \\
\hline PIK3CA & $5^{\prime}$-TGTGGGACTTATTGAGG-3' & $5^{\prime}$-CACCATGATGTGCATCATTCA- $3^{\prime}$ & 617 \\
\hline GAPDH & $5^{\prime}$-GGGTGTGAACCATGAGAAGT- $3^{\prime}$ & $5^{\prime}$-GGCATGGACTGTGGTCATGA-3' & 143 \\
\hline
\end{tabular}

2.8. Animal Study. Z138 cells $\left(10 \times 10^{6}\right.$ cells/animal $)$ were injected subcutaneously into the subscapularis of 4-week-old male nu/nu nude mice (National Rodent Laboratory Animal Resource, Beijing Branch, China). The tumor volume $(V)$ was calculated using the formula $V=$ [tumor length in $\mathrm{mm} \times$ (tumor width ${ }^{2}$ in $\mathrm{mm}$ )]/2. The xenografts of Z138 cells were grown to $100 \mathrm{~mm}^{3}$ and were treated with NCTD $(20 \mathrm{mg} / \mathrm{kg}$, IP, $3 \times$ per/week for four weeks) or normal saline (100 $\mu \mathrm{L}$, IP, $3 \times$ per/week for four weeks; $n=8 /$ group). Tumor growth and animal body weights were monitored twice a week. Four hours after the last dose, mice were euthanized and the tumor xenografts were removed for immunohistochemical (IHC) and TUNEL analyses. The use of animals for research was approved by the Committee of Research Animals in the Third Hospital of Hebei Medical University.

2.9. TUNEL Assay. The TUNEL assay was used to detect apoptosis in tumor tissue (DeadEnd Colorimetric Apoptosis Detection System, Promega Biotech Co., Ltd.). Briefly, $5 \mu \mathrm{m}$ paraffin-embedded sections were treated with $20 \mu \mathrm{g} / \mathrm{mL}$ proteinase K. DNA was end-labeled using Biotinylated Nucleotide Mix in TdT buffer at $37^{\circ} \mathrm{C}$ for $60 \mathrm{~min}$. DNA strand breaks were visualized using DAB. Apoptotic cells were quantified by determining the percentage of apoptotic cells per field.

2.10. Immunohistochemical Analysis of NF- $\kappa B$. Immunohistochemical analysis of NF- $\kappa \mathrm{B}$ was performed as previously described [13]. Two independent pathologists who were blinded to the treatment groups reviewed the sections under a light microscope with $\times 40$ power. Ten fields of interest were selected, and the percentage of immunohistochemically positive cells was determined for each selected field. The average percentage of positive cells for all fields was calculated and summarized as mean $\pm \mathrm{SD}$.

2.11. Statistical Analysis. The data were expressed as the mean \pm SD and were analyzed using SPSS 16.0 software. Comparisons between groups were made using one-way or two-way ANOVA tests followed by Bonferroni post hoc tests. Differences were considered significant at $P<0.05$. All statistical tests were two-sided.

\section{Results}

3.1. NCTD-Induced Antiproliferative and Proapoptotic Effects in MCL Cells. MTS analysis showed that NCTD treatment resulted in significant time- and dose-dependent growth inhibition of both Z138 and Mino cells (Figure 1(a)). NCTD also induced dose-dependent cytotoxicity in primary MCL cells from six patients with de novo MCL (Figure 1(b)). Flow cytometry to detect NCTD-induced apoptosis revealed increased percentage of early and late apoptotic cells in both MCL cell lines (Figure 1(c)). Apoptosis was also confirmed by the appearance of PARP cleavage (Figure 1(d)).

3.2. NCTD-Induced Apoptosis Involves Caspase Activity. To elucidate the molecular mechanisms by which NCTD induces apoptosis in MCL, we analyzed caspase action. NCTD treatment increased the activities of caspase- $3,-8$, and -9 in a time- and dose-dependent manner (Figure 2(a)). To determine whether NCTD-induced apoptosis was caspase dependent, the specific pan-caspase inhibitor Z-VAD $(50 \mu \mathrm{M})$ was added $1 \mathrm{~h}$ before the addition of $5 \mu \mathrm{M}$ NCTD. Flow cytometry analysis showed that Z-VAD completely abrogated NCTD-induced apoptosis (Figure 2(b)).

3.3. MCL Cell Proliferation Is Inhibited due to G1 Arrest. To determine whether cell growth arrest was associated with NCTD treatment in MCL cells, cell cycle analyses were performed. NCTD treatment dose dependently resulted in an increased number of cells in the G1 phase of the cell cycle, with a concomitant reduction of cells in $S$ phase (Figure 2(c)).

3.4. NCTD Downregulated NF- $\kappa B$ by Preventing NF- $\kappa B$ Phosphorylation and Nuclear Translocation. Previous studies have demonstrated that NF- $\kappa$ B is constitutively active in MCL and that constitutive NF- $\kappa$ B activation plays a key role in cell drug resistance MCL [14]. Therefore, we examined whether NCTD could reduce the constitutive NF- $\kappa \mathrm{B}$ activity in MCL cells. NCTD treatment downregulated the nuclear expressions of NF- $\kappa$ B p 65 and phosphorylated NF- $\kappa$ B p 65 . The expression of NF- $\kappa$ B p 65 in cytoplasm was not affected by NCTD (Figures 3(a) and 3(b)).

Nuclear translocation of NF- $\kappa \mathrm{B}$ occurs as a result of NF- $\kappa \mathrm{B}$ phosphorylation as well as $\mathrm{I} \kappa \mathrm{B} \alpha$ phosphorylation and degradation. Upon entering the nucleus, NF- $\kappa \mathrm{B}$ can bind DNA and cause gene transcription $[15,16]$. We found that NCTD treatment inhibited $\mathrm{I} \kappa \mathrm{B} \alpha$ phosphorylation and increase total $\mathrm{I} \kappa \mathrm{B} \alpha$ in MCL cell cytoplasm (Figures 3(a) and $3(\mathrm{~b})$ ), thus inhibiting NF- $\kappa \mathrm{B}$ nuclear translocation. These results suggest that NCTD can sequester $\mathrm{I} \kappa \mathrm{Ba}$ in the nucleus, resulting in the functional inactivation of NF- $\kappa$ B. 

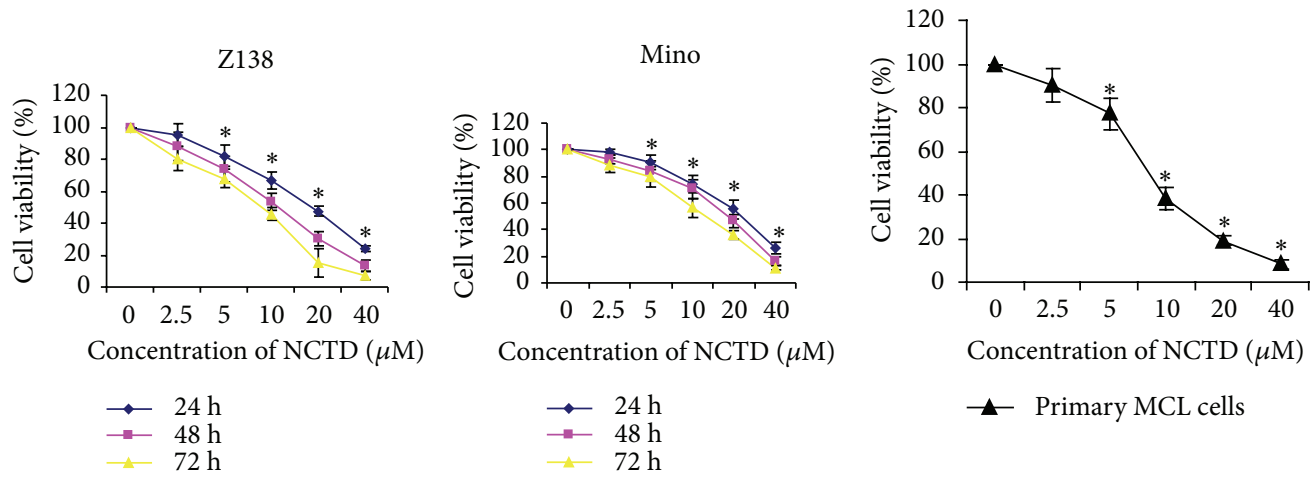

(a)

(b)
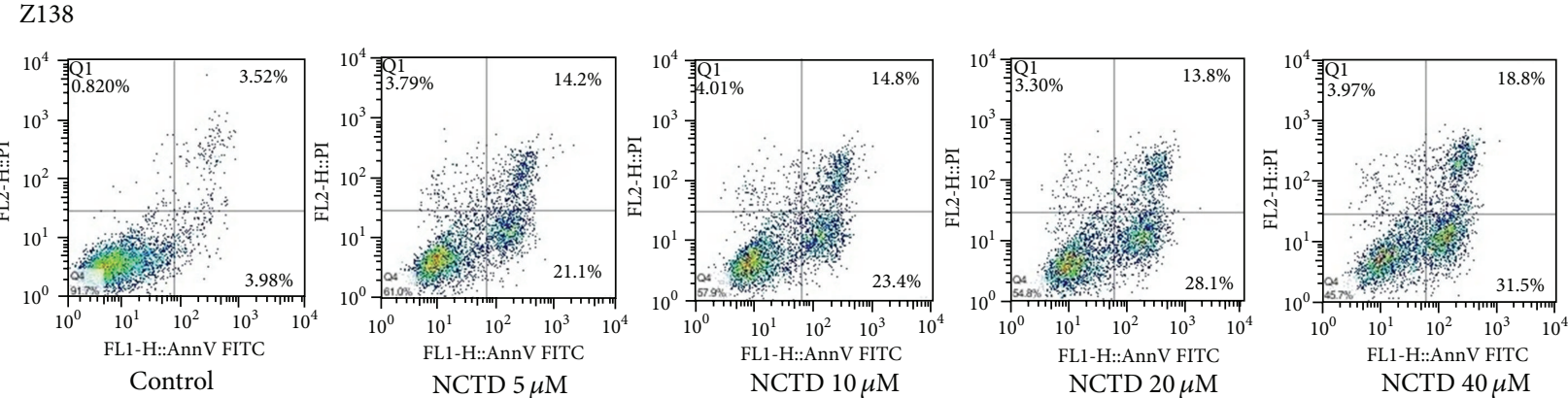

Mino
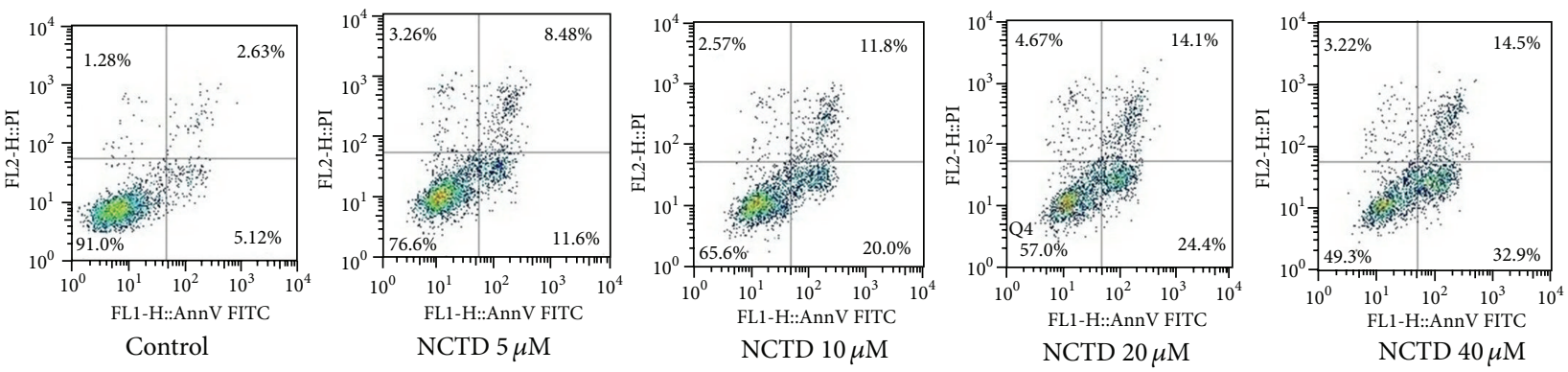

(c)
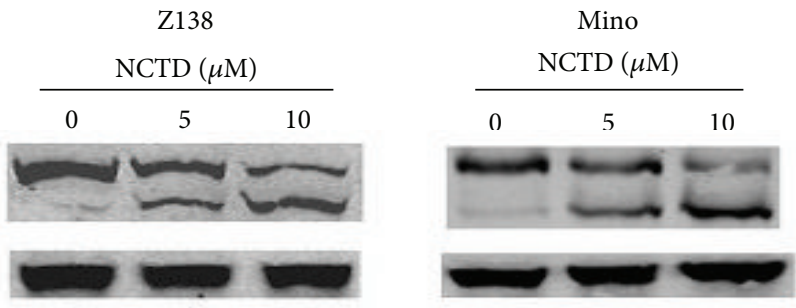

(d)

FIGURE 1: NCTD inhibited proliferation and induced apoptosis in MCL cells. (a) Z138 and Mino cells were treated with various concentrations of NCTD for 24, 48, and $72 \mathrm{~h}$, and then cell viability was measured by MTS assay. (b) Primary MCL cells from six patients were treated with NCTD for $48 \mathrm{~h}$ and then by MTS assay. (c) Z138 and Mino cells were treated with different concentration of NCTD (0-20 $\mu \mathrm{M})$ for $24 \mathrm{~h}$, and then apoptosis was detected using an annexin V/PI assay followed by flow cytometry. (d) PARP and cleaved PARP were determined by western blot. Experiments were performed in triplicate. Data are representative of three independent experiments. ${ }^{*} P<0.05$ versus control. 

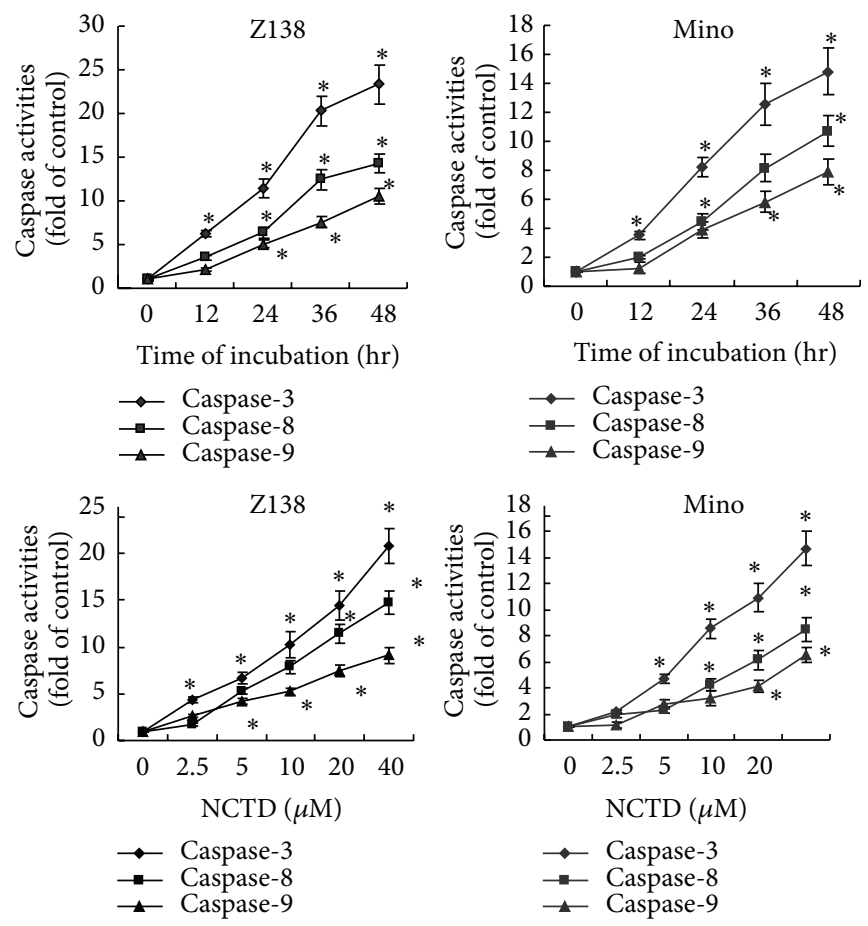

(a)
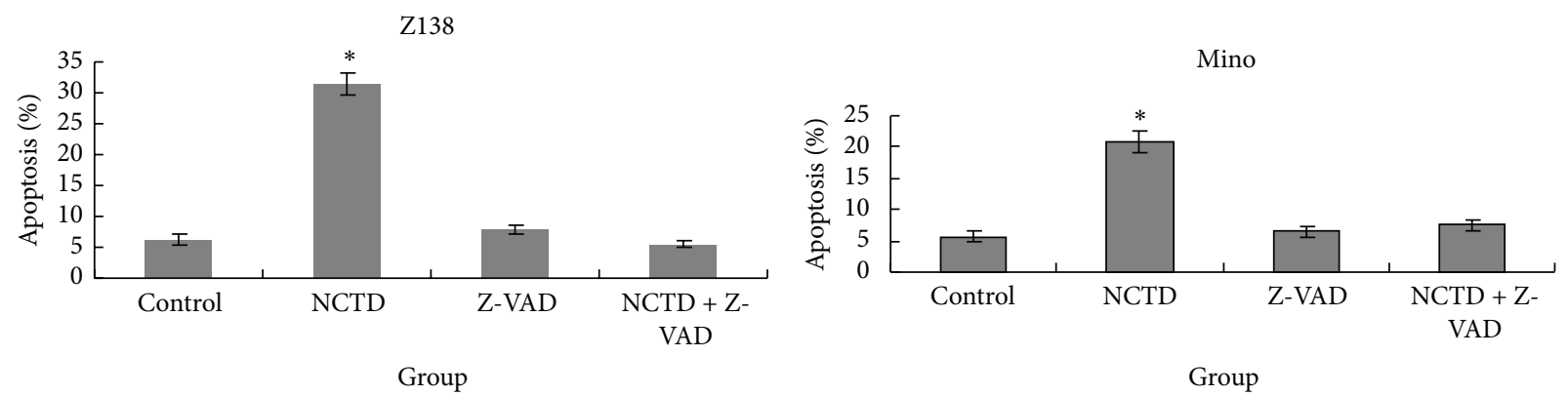

(b)
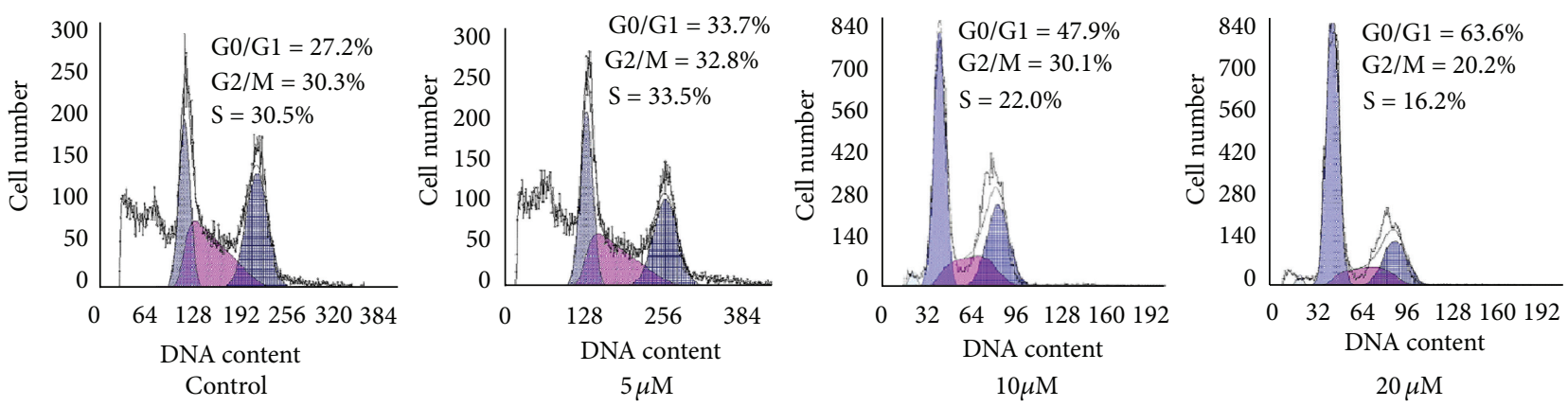

(c)

FIGURE 2: NCTD-induced caspase activities and G2/M arrest in MCL cells. (a) Z138 and Mino cells were treated with different concentrations of NCTD $(0-40 \mu \mathrm{M})$ for $24 \mathrm{~h}$ or with $5 \mu \mathrm{M}$ NCTD for $0,12,24,36$, and $48 \mathrm{~h}$. Spectrophotometry was used to determine the activities of caspase-3, -8, and -9. (b) Z138 and Mino cells were preincubated with the pancaspase inhibitor Z-VAD-FMK (50 $\mu \mathrm{M})$ for $1 \mathrm{~h}$ before treatment with $5 \mu \mathrm{M}$ NCTD for $24 \mathrm{~h}$, followed by the annexin V-PI assay. (c) Z138 cells were treated with different concentrations of NCTD (0, 5, 10, and $20 \mu \mathrm{M}$ ) for $24 \mathrm{~h}$, and then cell cycle analysis was performed using flow cytometry. Experiments were performed in triplicate. Data are represented as the mean $\pm \mathrm{SD}(n=3) .{ }^{*} P<0.05$ versus control group. 


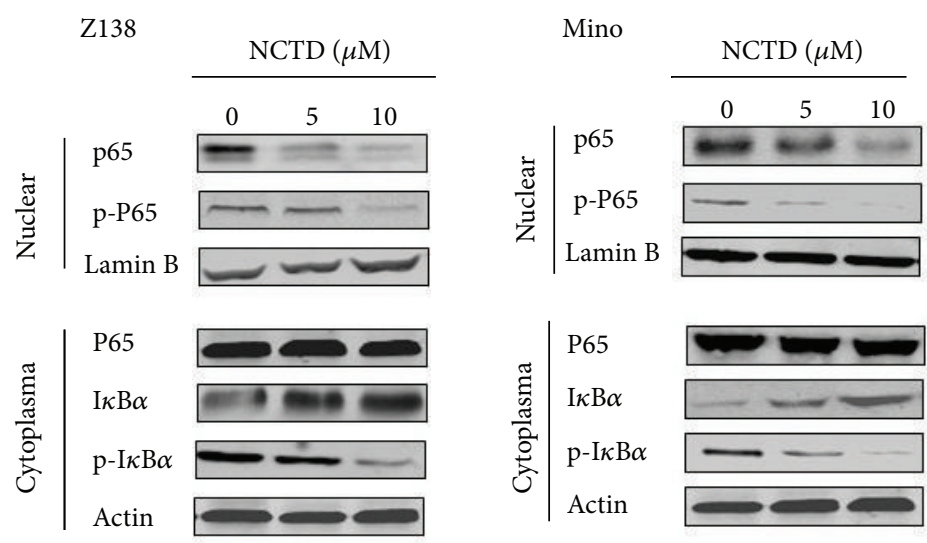

(a)
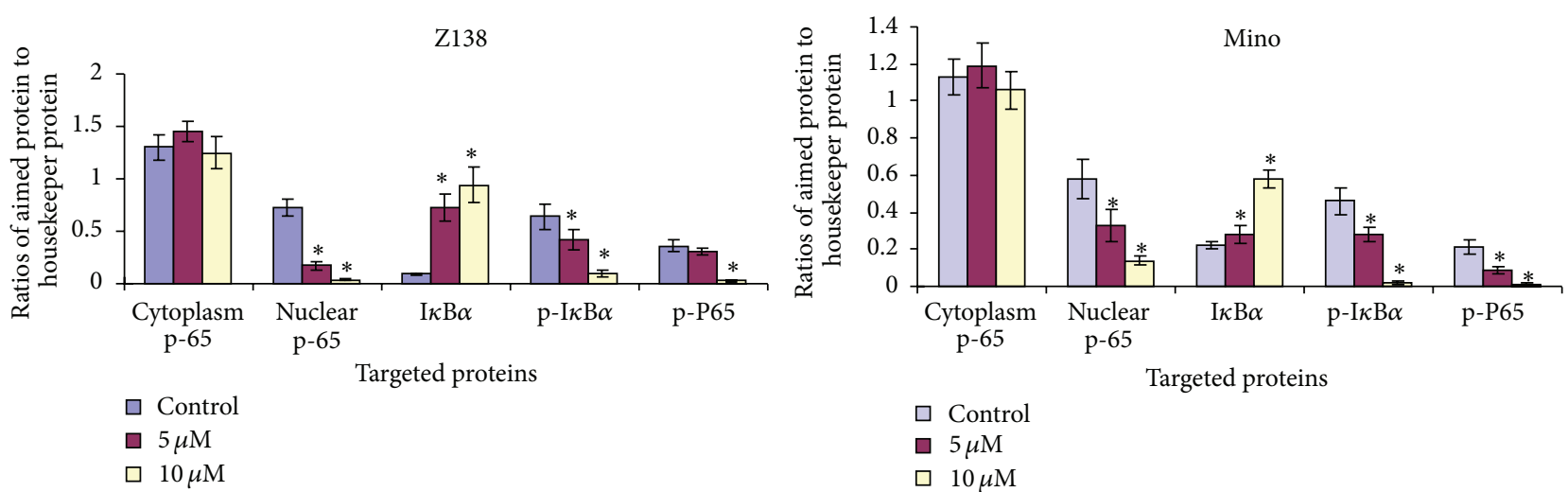

(b)

FIGURE 3: NCTD downregulated NF- $\kappa$ B by preventing NF- $\kappa$ B phosphorylation and nuclear translocation. Z138 and Mino cells were treated with $5 \mu \mathrm{M}$ NCTD for $24 \mathrm{~h}$. (a) The protein expressions of NF- $\kappa \mathrm{B}$ p65, p-P65, I $\kappa \mathrm{B} \alpha$, and $\mathrm{p}-\mathrm{I} \kappa \mathrm{B} \alpha$ were detected by western blot analysis. (b) Quantitative data of (a). Statistical analysis was carried out using the ANOVA and Bonferroni tests. ${ }^{*} P<0.05$ versus control.

3.5. NCTD Also Downregulates NF- $\kappa$ B-Regulated Gene Products. Numerous proteins-including cyclin D1, BAX, survivin, Bcl-2, XIAP, and cIAP1-are regulated by NF- $\kappa$ B and correlate with chemoresistance and apoptosis. We investigated whether the antilymphoma effects of NCTD were mediated by downregulated expression of NF- $\kappa \mathrm{B}$-regulated products that are implicated in cell proliferation and apoptosis. Our results showed that NCTD downregulated the expressions of all of these molecules in protein level (Figures 4(a) and 4(b)) and gene level (Figure 4(c)).

3.6. PI3K/Akt Survival Pathway Inactivation Is Associated with NCTD-Mediated Apoptosis. We further investigated the PI3K/Akt survival pathway, which is known to affect the NF- $\kappa$ B signal pathway, cyclin D1, and the IAP family. After treatment with NCTD for $24 \mathrm{~h}$, there was a dose-dependent decrease in the levels of PI3Kp110 $\alpha$ and p-Akt, while total Akt remained unchanged (Figure 5(a)). The time- and dosedependent inhibition of PI3Kp110 $\alpha$ expression after exposure to NCTD was further confirmed at the mRNA level (Figure 5(b)).
To further verify the role of the PI3K/Akt pathway on NCTD-induced apoptosis, MCL cells were treated with NCTD in the presence or absence of the PI3K inhibitor LY294002 $(50 \mu \mathrm{mol} / \mathrm{L})$. NCTD combined with LY294002 significantly inhibited the expression of p-Akt and therefore downregulated expression of p-P65 and cyclin D1 (Figures $5(c)$ and 5(d)).

3.7. NCTD Has Antilymphoma Effects In Vivo. Next, the antilymphoma effects of NCTD were evaluated in vivo. In an MCL-bearing mouse model established in nude mice, tumor growth was significantly inhibited by $20 \mathrm{mg} / \mathrm{kg}$ NCTD $(P=0.03$, Figure 6(a) $)$. With respect to the untreated control group, the tumor volume reduction rates were $37.4 \%$ in the NCTD group. Mouse body weight did not significantly change during the experiment.

The TUNEL assay was used to detect apoptosis induced by NCTD. Our results revealed remarkably more frequent apoptosis in tumors harvested from the NCTD-treated animals than from the control group $(P=0.0011$ and $P=$ 0.0017; Figures 6(b) and 6(c)), demonstrating that NCTD effectively induced apoptosis in xenograft lymphoma tissues. 

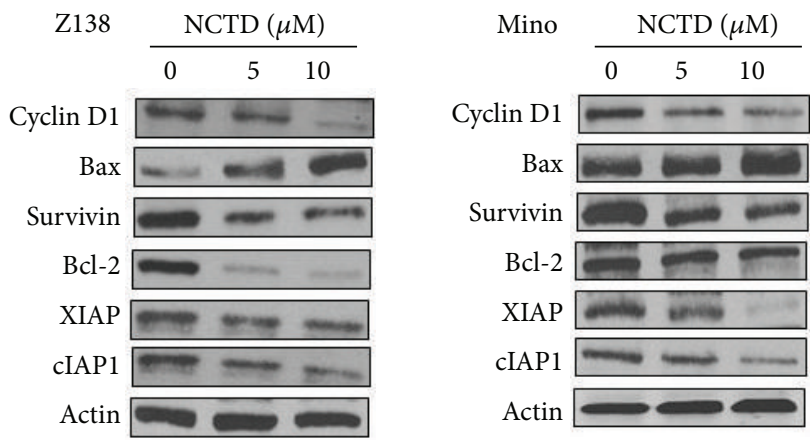

(a)
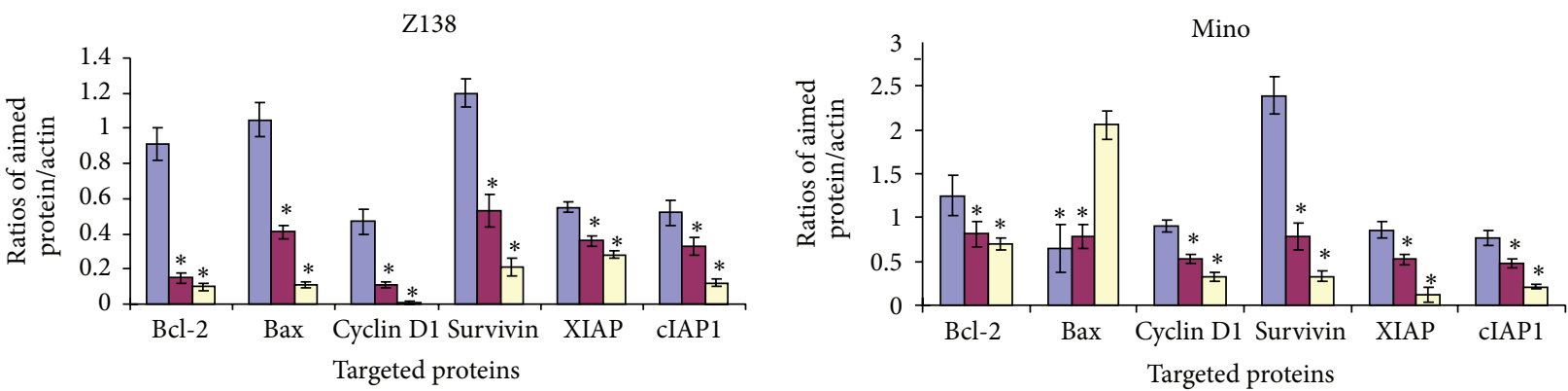

$$
\begin{aligned}
& \text { ․ Control } \\
& \text { } 5 \mu \mathrm{M} \\
& \text { } 10 \mu \mathrm{M}
\end{aligned}
$$
$\square$ Control
- $5 \mu \mathrm{M}$
ㅁ $10 \mu \mathrm{M}$

(b)

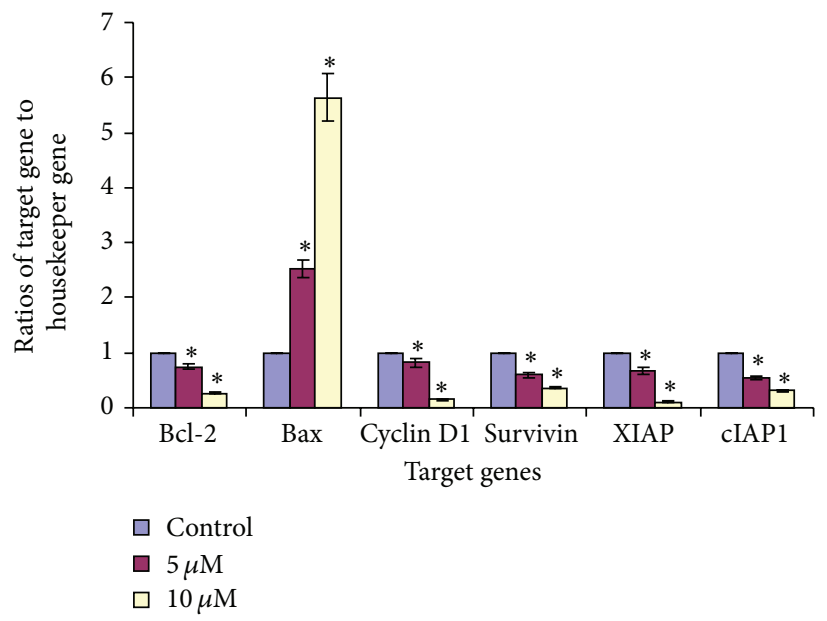

(c)

FIGURE 4: NF- $\kappa$ B-regulated gene products were downregulated by NCTD. Z138 and Mino cells were treated with 0,5 , and $10 \mu \mathrm{M}$ NCTD for $24 \mathrm{~h}$. (a) Western blot was used to analyze the expressions of Bcl-2, BAX, cyclin-D1, survivin, XIAP, and cIAP1. (b) Quantitative data of (a). (c) Z138 cells were treated with different concentrations of $\operatorname{NCTD}(0,5$, and $10 \mu \mathrm{M})$ for $24 \mathrm{~h}$, and then RT-qPCR was used to determine the mRNA expressions of Bcl-2, BAX, cyclin-D1, survivin, XIAP, and cIAP1. Statistical analysis was carried out using the ANOVA and Bonferroni tests. ${ }^{*} P<0.05$ versus control.

To verify the NCTD-mediated prevention of NF- $\kappa \mathrm{B}$ nuclear translocation in the animal model, we used IHC to detect NF- $\kappa$ B p 65 expression before and after NCTD treatment. Our data showed that NCTD treatment downregulated the nuclear expression of NF- $\kappa$ B p 65 , suggesting that NCTD inhibited the nuclear translocation of NF- $\kappa$ B.

\section{Discussion}

The present study investigated the antitumor activity of NCTD against MCL. NCTD treatment resulted in dosedependent cytotoxicity in Z138 and Mino cells as well as in primary MCL cells from six patients with de novo MCL. 

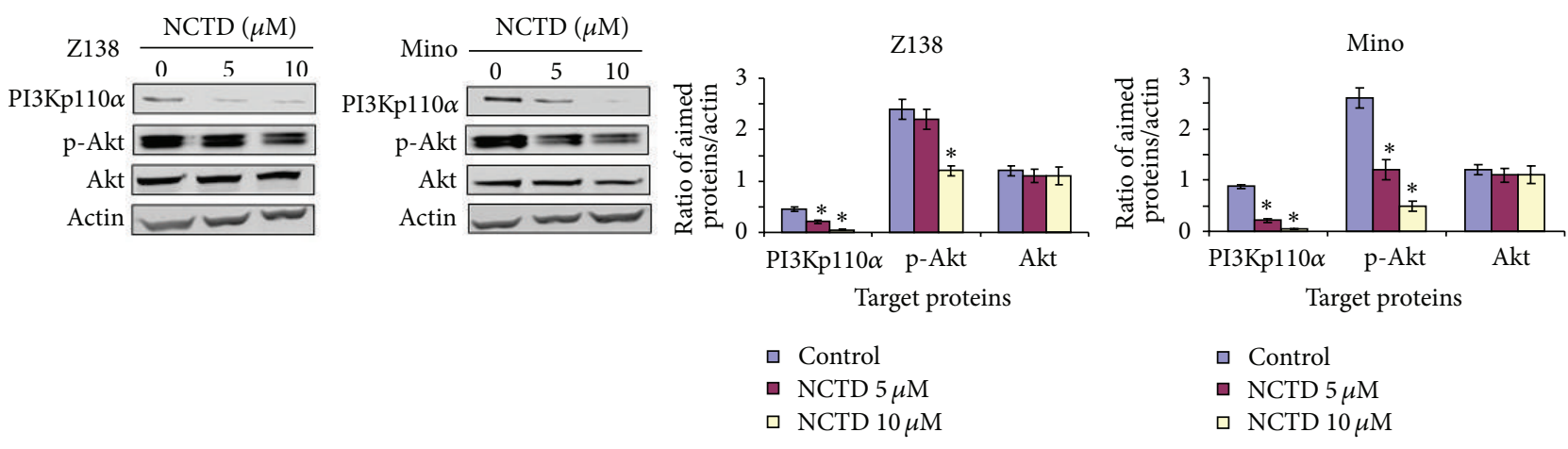

(a)

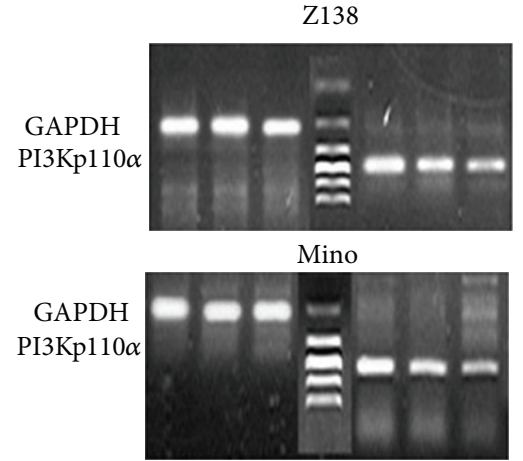

(b)
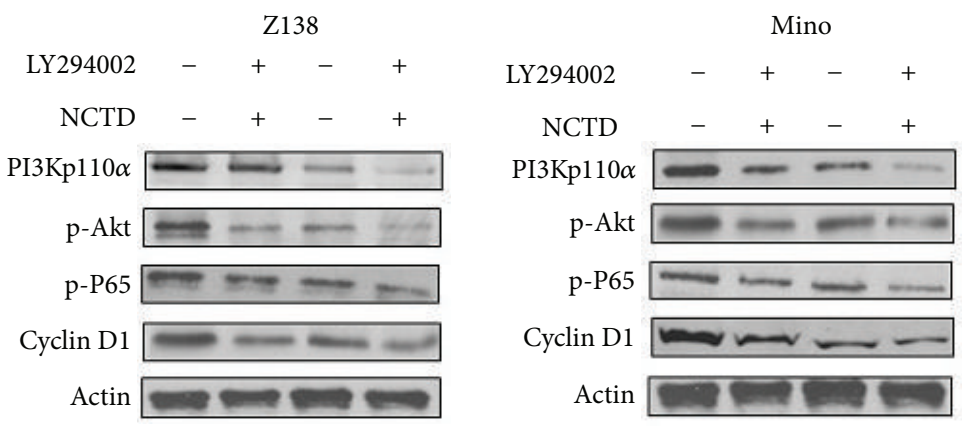

(c)
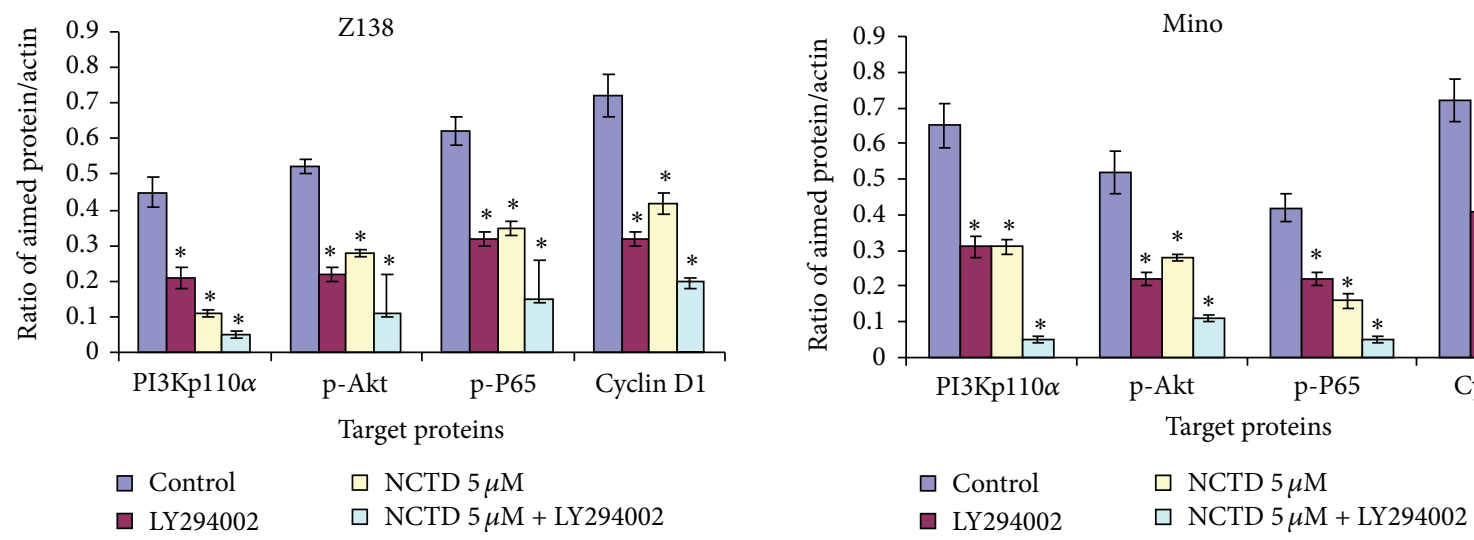

(d)

FIGURE 5: The PI3K/Akt survival pathway was associated with NCTD-mediated apoptosis. Z138 and Mino cells were treated with $5 \mu \mathrm{M}$ NCTD for $24 \mathrm{~h}$. (a) Left, western blot was used to analyze the expressions of PI3Kp110 $\alpha$, p-Akt, and Akt. Right, quantitative data from these western blots for three independent experiments. (b) Inhibition of PI3Kp110 $\alpha$ expression was confirmed at the mRNA level. (c) Z138 and Mino cells were preincubated with $50 \mu \mathrm{mol} / \mathrm{L}$ LY294002 for $1 \mathrm{~h}$ before treatment of $5 \mu \mathrm{M}$ NCTD for $24 \mathrm{~h}$. NCTD combined with LY294002 led to significant inhibition of the expression of PI3Kp110 $\alpha$, p-Akt, NF- $\kappa$ B p-P65, and cyclin D1 proteins. (d) Quantitative data of (c). ${ }^{*} \mathrm{P}<0.05$ versus control.

The anti-lymphoma effect of NCTD was confirmed in animal model also. Further experiments aimed to elucidate the mechanisms behind this effect.

MCL exhibits a complex pathobiology that includes cyclin D1 overexpression, abnormalities in the DNA damage response, and dysregulation of the PI3K/Akt and NF- $\kappa \mathrm{B}$ cell survival pathways $[1,17]$. Activation of the PI3K/AKT pathway is a critical step in cell survival. AKT is a serine threonine kinase that regulates cell survival, proliferation, and apoptosis [1, 18-20], and constitutive AKT activation is reportedly essential to the pathogenesis and survival of MCL [21-23]. Previous in vitro testing of MCL cell lines with Akt inhibitors resulted in apoptosis via a caspase-dependent mechanism $[23,24]$. Given the central role of the PI3K/AKT pathway in MCL, the present study examined the effects of NCTD on PI3K/Akt pathway regulation.

Akt is activated by phosphorylation, which is mediated by the direct binding of lipid second messengers, such as 


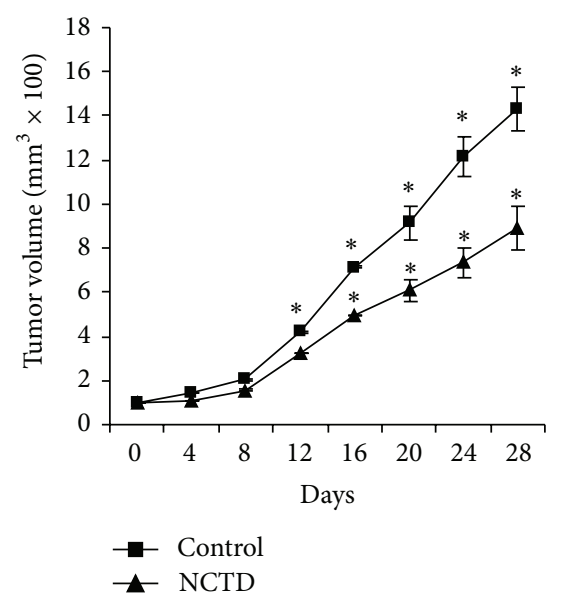

(a)

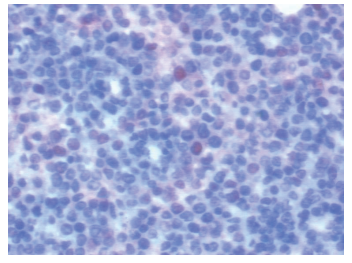

Control

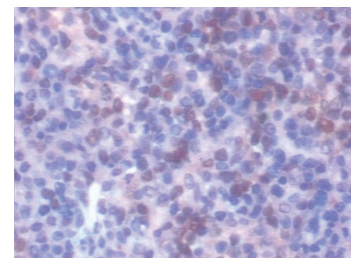

NCTD

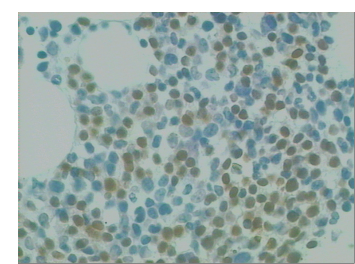

Control

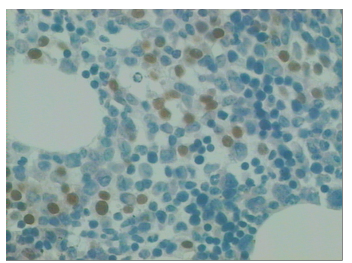

NCTD

(b)

(c)

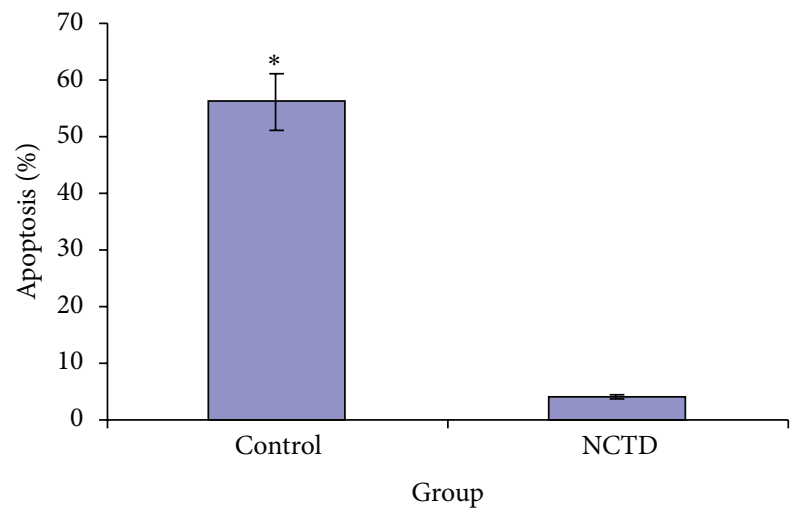

(d)

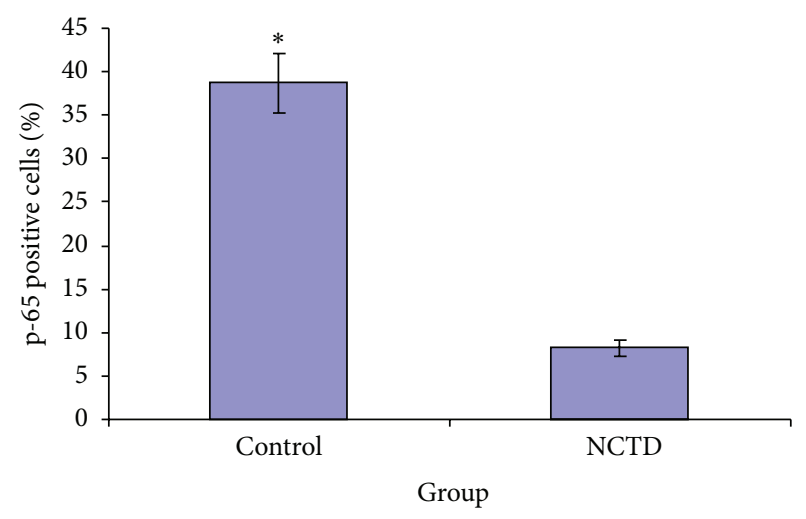

(e)

FIGURE 6: NCTD significantly inhibited Z138 nude mice xenografts. (a) Median tumor volumes of xenografts in mice receiving vehicle control or $20 \mathrm{mg} / \mathrm{kg}$ NCTD. Data represent mean \pm SD of eight nude mice in each group. Statistical analysis was carried out performed using the ANOVA and Bonferroni tests. ${ }^{*} P<0.05$ versus control. (b) Cell apoptosis determined by TUNEL method in MCL tumor samples. (c) Immunohistochemical analysis of NF- $\kappa$ B expression in MCL mouse xenografts (400x). (d) Quantitative data of (b). (e) Quantitative data of (c). ${ }^{*} P<0.05$ versus control.

phosphatidylinositol-3,4-bisphosphate (Ptdins(3,4)P2) and phosphatidylinositol-3,4,5-trisphosphate (Ptdins $(3,4,5) \mathrm{P} 3)$, which are generated by PI3K [25]. Akt activation can be induced by amplification of the PIK3CA gene, which has been implicated as a potential predictive oncogene in tumors [26]. Our present data showed that NCTD inhibited Akt activation through inhibition of PIK3CA gene transcription. The PI3K inhibitor LY294002 initiated the blockade of Akt signaling, thus inhibiting Akt phosphorylation. Combination with LY294002 potentiated the ability of NCTD to induce apoptosis of MCL cells and significantly downregulated
Akt phosphorylation, indicating that inactivation of the PI3K/Akt survival pathway played an important role in NCTD-induced MCL cell death.

$\mathrm{PI} 3 \mathrm{~K}$ can regulate NF- $\kappa \mathrm{B}$ activation by the tyrosine phosphorylation-dependent pathway, thereby releasing NF$\kappa \mathrm{B}$ to translocate to the nucleus [27]. Constitutive activation of NF- $\kappa \mathrm{B}$ is observed in MCL $[1,28,29]$. Here, we found that NCTD inhibited NF- $\kappa$ B activity by blocking NF- $\kappa$ B phosphorylation and nuclear translocation. When combined with LY294002, NCTD significantly affected NF- $\kappa$ B P65 phosphorylation, confirming that NCTD negatively regulates 
NF- $\kappa$ B activity through inactivation of the PI3K/Akt survival pathway.

Cyclin D1 is overexpressed in MCL and is of paramount importance in determining the biological character of MCL. Recent studies show that NF- $\kappa \mathrm{B}$ transcriptionally regulates cyclin DI gene expression [30]. In our studies, we found that NCTD decreased cyclin D1 expression and that this inhibition was enhanced when NCTD was combined with LY294002. Thus, it is possible that NCTD prevents cyclin $\mathrm{D} 1$ expression by targeting the $\mathrm{PI} 3 \mathrm{~K} / \mathrm{Akt} / \mathrm{NF}-\kappa \mathrm{B}$ signaling pathway.

Numerous proteins - such as survivin, XIAP, BAX, cIAP1, and $\mathrm{Bcl}-2$ - are regulated by $\mathrm{NF}-\kappa \mathrm{B}$ and expressed in correlation with apoptosis and chemoresistance. Here we investigated whether the antitumor effects of NCTD were mediated by altered expressions of NF- $\kappa \mathrm{B}$-regulated proteins that are implicated in cell proliferation and apoptosis. Our results showed that NCTD downregulated the expression of antiapoptosis proteins (e.g., survivin, XIAP, cIAP1, and Bcl-2), and upregulated the expression of the proapoptosis protein BAX.

The anti-lymphoma effect of NCTD was also confirmed in a mouse model. NCTD treatment inhibited the growth of Z138 xenografts in nude mice, with concomitant decrease of the nuclear expression of NF- $\kappa \mathrm{B}$ p65. This finding further supports our hypothesis that inhibition of NF- $\kappa$ B activity may be involved in the anti-lymphoma activity of NCTD in MCL.

\section{Conclusion}

The present preclinical study demonstrates the in vitro and in vivo antitumor activity of NCTD in MCL. NCTD induced marked antiproliferative and proapoptotic effects in MCL cells through modulation of the PI $3 \mathrm{~K} / \mathrm{Akt} / \mathrm{NF}-\kappa \mathrm{B}$ pathway. These results support the rationale for clinical investigation of the potential therapeutic value of NCTD for MCL treatment.

\section{Authors' Contribution}

Yan Li, Jie Fang and Hengfei Du performed all experiments and summarized the data. Hongyan Lv and Xiaoning Song made critical comments for the paper; Jinqiao Zhang contributed to the conceptual idea for the work, designed experiments, and wrote and edited the paper. All authors read and approved the final paper.

\section{Conflict of Interests and Source of Funding}

The authors declare that there were no conflicts of interest for the current work. This work was supported in part by a grand from the Bureau of Health of Hebei Province, China (no. 2007136) to Jinqiao Zhang.

\section{Acknowledgment}

This work was supported in part by funds from the Bureau of Health of Hebei Province, China, to Jinqiao Zhang (Grant no. 2007136).

\section{References}

[1] L. Alinari, B. Christian, and R. A. Baiocchi, "Novel targeted therapies for mantle cell lymphoma," Oncotarget, vol. 3, no. 2, pp. 203-211, 2012.

[2] A. Herrmann, E. Hoster, T. Zwingers et al., "Improvement of overall survival in advanced stage mantle cell lymphoma," Journal of Clinical Oncology, vol. 27, no. 4, pp. 511-518, 2009.

[3] P. Martin, A. Chadburn, P. Christos et al., "Intensive treatment strategies may not provide superior outcomes in mantle cell lymphoma: overall survival exceeding 7 years with standard therapies," Annals of Oncology, vol. 19, no. 7, pp. 1327-1330, 2008.

[4] M. E. Williams, M. Dreyling, J. Winter, S. Muneer, and J. Leonard, "Management of mantle cell lymphoma: key challenges and next steps," Clinical Lymphoma, Myeloma and Leukemia, vol. 10, no. 5, pp. 336-346, 2010.

[5] Y. Huang, Q. Liu, K. Liu, K. Yagasaki, and G. Zhang, "Suppression of growth of highly-metastatic human breast cancer cells by norcantharidin and its mechanisms of action," Cytotechnology, vol. 59, no. 3, pp. 201-208, 2009.

[6] C. Chang, Y. Zhu, X. Tang, and W. Tao, "The anti-proliferative effects of norcantharidin on human HepG2 cells in cell culture," Molecular Biology Reports, vol. 38, no. 1, pp. 163-169, 2011.

[7] J. Luan, H. Duan, Q. Liu, K. Yagasaki, and G. Zhang, "Inhibitory effects of norcantharidin against human lung cancer cell growth and migration," Cytotechnology, vol. 62, no. 4, pp. 349-355, 2010.

[8] Y.-J. Chen, W.-M. Chang, Y.-W. Liu et al., "A small-molecule metastasis inhibitor, norcantharidin, downregulates matrix metalloproteinase-9 expression by inhibiting Spl transcriptional activity in colorectal cancer cells," Chemico-Biological Interactions, vol. 181, no. 3, pp. 440-446, 2009.

[9] Y.-J. Chen, C.-D. Kuo, Y.-M. Tsai, C.-C. Yu, G.-S. Wang, and H.-F. Liao, "Norcantharidin induces anoikis through Jun-Nterminal kinase activation in CT26 colorectal cancer cells," AntiCancer Drugs, vol. 19, no. 1, pp. 55-64, 2008.

[10] H.-F. Liao, S.-L. Su, Y.-J. Chen, C.-H. Chou, and C.-D. Kuo, "Norcantharidin preferentially induces apoptosis in human leukemic Jurkat cells without affecting viability of normal blood mononuclear cells," Food and Chemical Toxicology, vol. 45, no. 9, pp. 1678-1687, 2007.

[11] X.-H. Liu, I. Blazsek, M. Comisso et al., "Effects of norcantharidin, a protein phosphatase type-2A inhibitor, on the growth of normal and malignant haemopoietic cells," The European Journal of Cancer A, vol. 31, no. 6, pp. 953-963, 1995.

[12] Y. M. Jiang, Z. Z. Meng, G. X. Yue et al., "Norcantharidin induces HL-60 cells apoptosis in vitro," Evidence-Based Complementary and Alternative Medicine, vol. 2012, Article ID 154271, 2012.

[13] H. F. Du, L. J. Yu, Y. F. Meng et al., "Norcantharidin enhances bortezomib-antimyeloma activity in multiple myeloma cells in vitro and in nude mouse xenografts," Leukemia Lymphoma, vol. 54, no. 3, pp. 607-618, 2013.

[14] A. Palumbo, M. Attal, and M. Roussel, "Shifts in the therapeutic paradigm for patients newly diagnosed with multiple myeloma: maintenance therapy and overall survival," Clinical Cancer Research, vol. 17, no. 6, pp. 1253-1263, 2011.

[15] A. S. Baldwin Jr., "The NF-kappa B and I kappa B proteins: new discoveries and insights," Annual Review of Immunology, vol. 14, pp. 649-683, 1996.

[16] T. Hideshima, D. Chauhan, P. Richardson et al., "NF- $\kappa$ B as a therapeutic target in multiple myeloma," Journal of Biological Chemistry, vol. 277, no. 19, pp. 16639-16647, 2002. 
[17] J. P. Leonard, M. E. Williams, A. Goy et al., "Mantle cell lymphoma: biological insights and treatment advances," Clinical Lymphoma \& Myeloma, vol. 9, no. 4, pp. 267-277, 2009.

[18] G. Song, G. Ouyang, and S. Bao, "The activation of Akt/PKB signaling pathway and cell survival," Journal of Cellular and Molecular Medicine, vol. 9, no. 1, pp. 59-71, 2005.

[19] L. C. Cantley, "The phosphoinositide 3-kinase pathway," Science, vol. 296, no. 5573, pp. 1655-1657, 2002.

[20] G. C. Fillmore, Q. Wang, M. J. Carey, C.-H. Kim, K. S. J. Elenitoba-Johnson, and M. S. Lim, "Expression of Akt (protein kinase B) and its isoforms in malignant lymphomas," Leukemia and Lymphoma, vol. 46, no. 12, pp. 1765-1773, 2005.

[21] W. K. Hofmann, S. de Vos, K. Tsukasaki et al., "Altered apoptosis pathways in mantle cell lymphoma detected by oligonucleotide microarray," Blood, vol. 98, no. 3, pp. 787-794, 2001.

[22] E. G. Rizzatti, R. P. Falcão, R. A. Panepucci et al., "Gene expression profiling of mantle cell lymphoma cells reveals aberrant expression of genes from the PI3K-AKT, WNT and TGF $\beta$ signalling pathways," The British Journal of Haematology, vol. 130, no. 4, pp. 516-526, 2005.

[23] M. Rudelius, S. Pittaluga, S. Nishizuka et al., "Constitutive activation of Akt contributes to the pathogenesis and survival of mantle cell lymphoma," Blood, vol. 108, no. 5, pp. 1668-1676, 2006.

[24] W. H. Chappell, L. S. Steelman, J. M. Long et al., "Ras/Raf/MEK/ERK and PI3K/PTEN/Akt/mTOR inhibitors: rationale and importance to inhibiting these pathways in human health," Oncotarget, vol. 2, no. 3, pp. 135-164, 2011.

[25] S. G. Kennedy, A. J. Wagner, S. D. Conzen et al., "The PI 3kinase/Akt signaling pathway delivers an anti-apoptotic signal," Genes and Development, vol. 11, no. 6, pp. 701-713, 1997.

[26] L. Shayesteh, Y. Lu, W. L. Kuo et al., "PIK3CA is implicated as an oncogene in ovarian cancer," Nature Genetics, vol. 21, no. 1, pp. 99-102, 1999.

[27] C. Béraud, W. J. Henzel, and P. A. Baeuerle, "Involvement of regulatory and catalytic subunits of phosphoinositide 3-kinase in NF-kappaB activation," Proceedings of the National Academy of Sciences of the United States of America, vol. 96, no. 2, pp. 429434, 1999.

[28] P. Pérez-Galán, M. Dreyling, and A. Wiestner, "Mantle cell lymphoma: biology, pathogenesis, and the molecular basis of treatment in the genomic era," Blood, vol. 117, no. 1, pp. 26-38, 2011.

[29] L. V. Pham, A. T. Tamayo, L. C. Yoshimura, P. Lo, and R. J. Ford, "Inhibition of constitutive NF- $\kappa$ B activation in mantle cell lymphoma B cells leads to induction of cell cycle arrest and apoptosis," Journal of Immunology, vol. 171, no. 1, pp. 88-95, 2003.

[30] I.-I. Witzel, L. F. Koh, and N. D. Perkins, "Regulation of cyclin D1 gene expression," Biochemical Society Transactions, vol. 38, no. 1, pp. 217-222, 2010. 


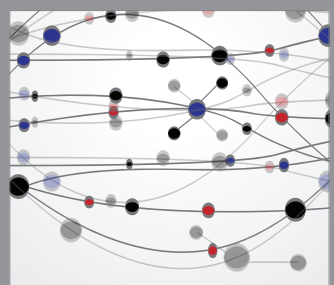

The Scientific World Journal
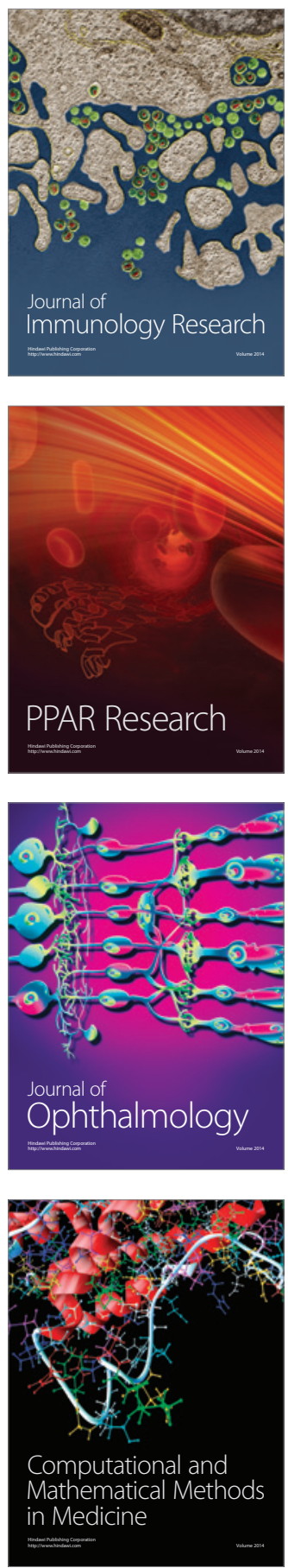

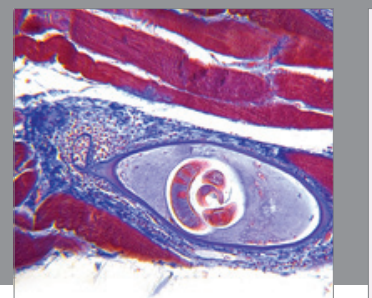

Gastroenterology

Research and Practice
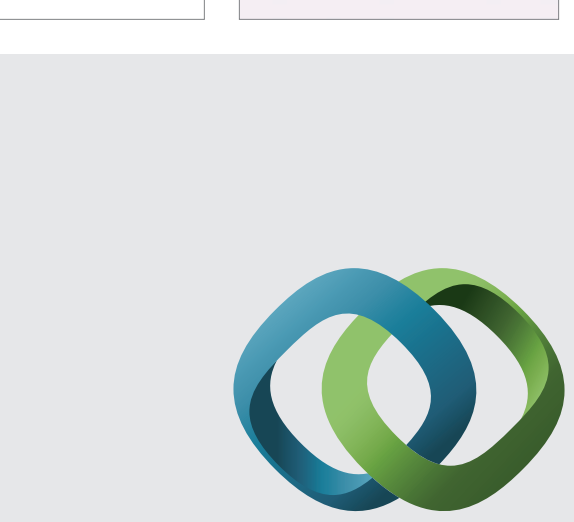

\section{Hindawi}

Submit your manuscripts at

http://www.hindawi.com
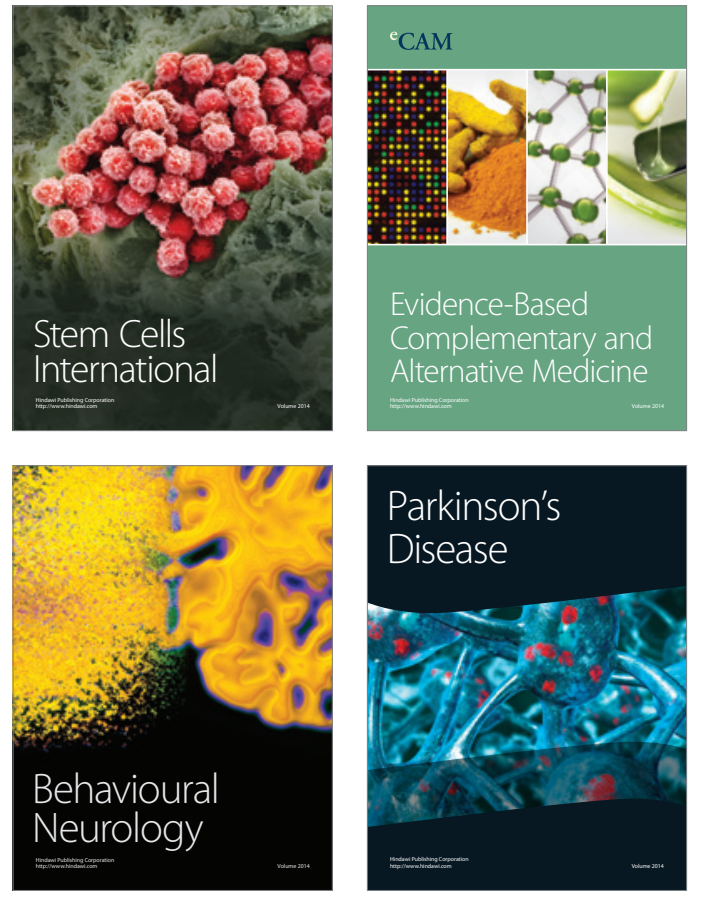
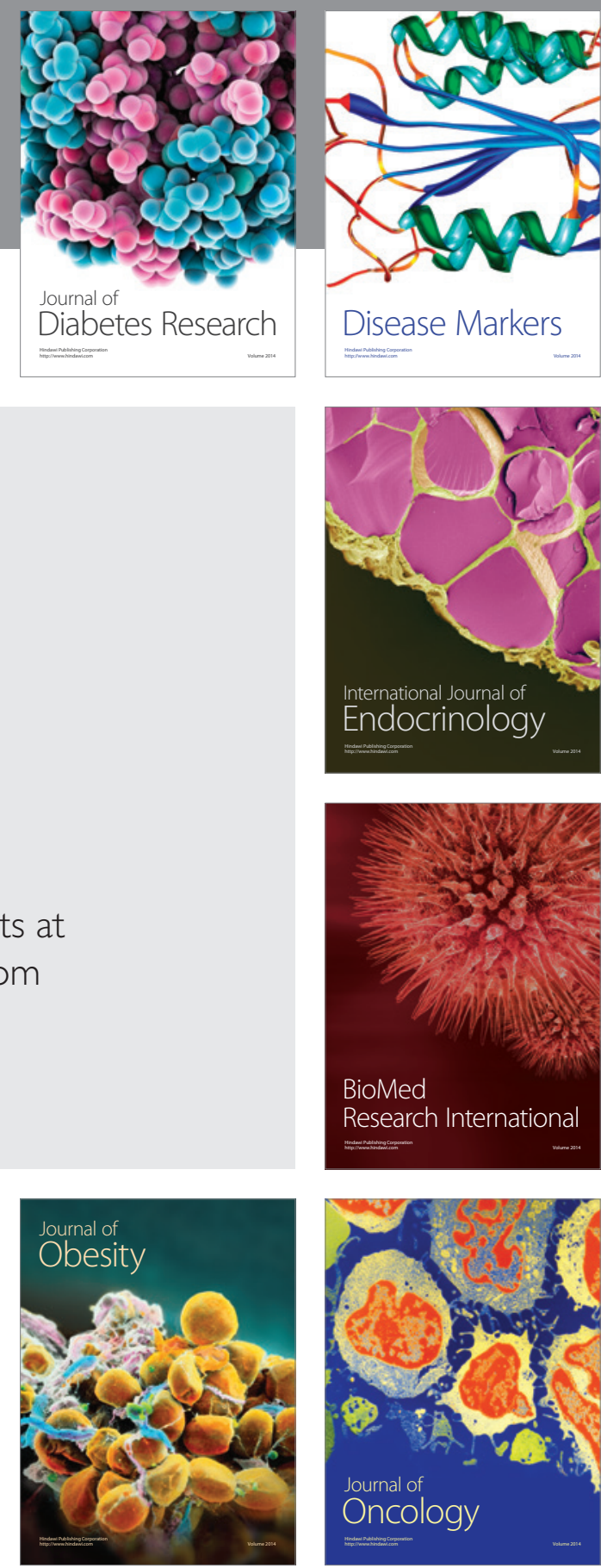

Disease Markers
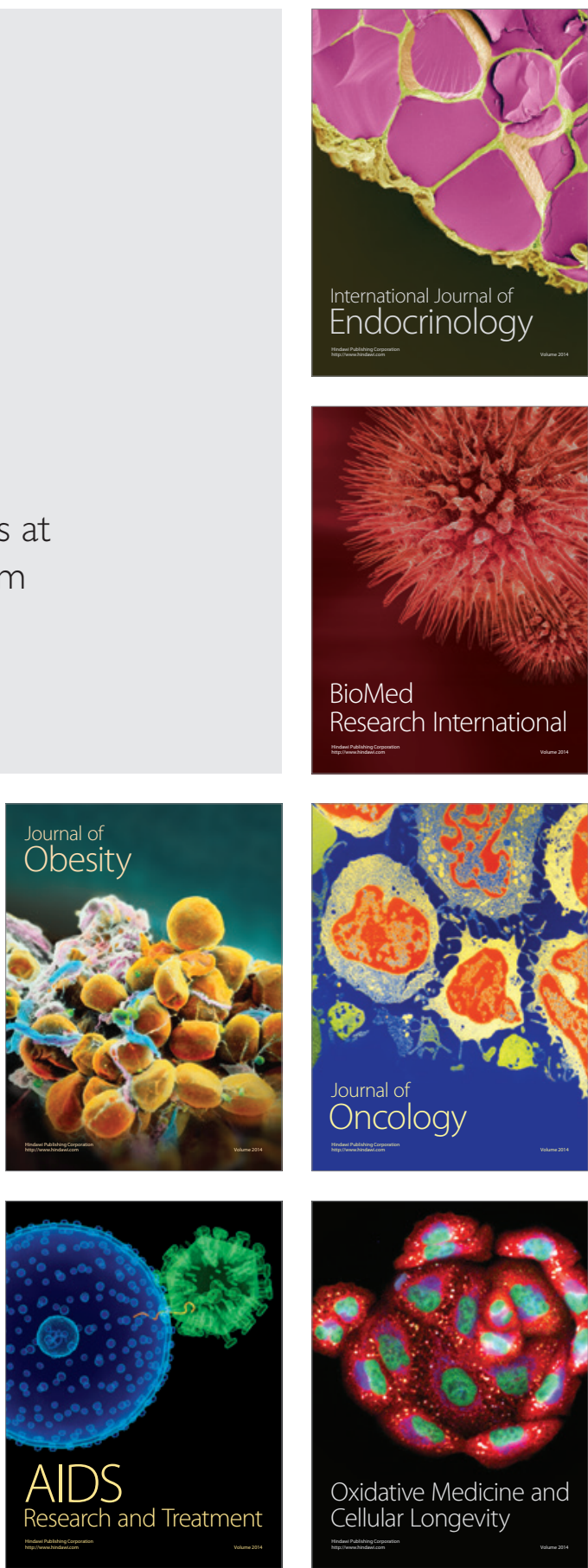